\title{
Comparison of outcomes from sepsis between patients with and without pre-existing left ventricular dysfunction: a case-control analysis
}

\author{
Daniel R Ouellette ${ }^{*}$ and Sadia Z Shah
}

\begin{abstract}
Introduction: The aim of this study was to determine if there are differences between patients with pre-existing left ventricular dysfunction and those with normal antecedent left ventricular function during a sepsis episode in terms of in-hospital mortality and mortality risk factors when treated in accordance with a sepsis treatment algorithm.

Methods: We performed a retrospective case-control analysis of patients selected from a quality improvement database of 1,717 patients hospitalized with sepsis between 1 January 2005 and 30 June 2010. In this study, 197 patients with pre-existing left ventricular systolic dysfunction and sepsis were compared to 197 case-matched patients with normal prior cardiac function and sepsis.

Results: In-hospital mortality rates $(P=0.117)$ and intubation rates at 24 hours $(P=0.687)$ were not significantly different between cases and controls. There was no correlation between the amount of intravenous fluid administered over the first 24 hours and the $\mathrm{PaO}_{2} / \mathrm{FiO}_{2}$ ratio at 24 hours in either cases or controls $\left(r^{2}=0.019\right.$ and $r^{2}=0.001$, respectively). Mortality risk factors for cases included intubation status ( $P=0.016, \mathrm{OR}=0.356$ for no intubation), compliance with a sepsis bundle ( $P=0.008, \mathrm{OR}=3.516$ for failed compliance), a source of infection other than the lung $(P=0.019$, $\mathrm{OR}=2.782)$, and the initial mixed venous oxygen saturation $(P=0.004, \mathrm{OR}=0.997)$. Risk factors for controls were the initial platelet count $(P=0.028, O R=0.997)$ and the serum lactate level $(P=0.048, O R=1.104)$. Patients with pre-existing left ventricular dysfunction who died had a lower initial mean mixed venous oxygen saturation than those who survived ( $61 \pm 18 \%$ versus $70 \pm 16 \%, P=0.002$ ).

Conclusions: Clinical outcomes were not different between septic patients with pre-existing left ventricular dysfunction and those with no cardiac disease. There was no correlation between fluid administration and oxygenation at 24 hours in either cohort. The mortality risk factor profile of patients with pre-existing left ventricular dysfunction was different when compared with control patients, and may be related to oxygen delivery determinants.
\end{abstract}

\section{Introduction}

Severe sepsis and septic shock represent serious medical conditions with high morbidity and mortality rates. Sepsis is a leading cause of death [1,2], and frequently causes end-organ damage [3], as well as cognitive and physical disability in survivors [4]. In the United States, over \$14 billion were spent on hospitalizations for sepsis in 2008 alone [5]. The hospitalization rate for sepsis has more than doubled between 2000 and 2008, with a rate of 24 per 10,000 persons in 2008 [2]. Patients hospitalized with sepsis have a length of stay nearly twice that of other

* Correspondence: douelle1@hfhs.org

Pulmonary and Critical Care Medicine, Henry Ford Hospital, K-17, 2799 West Grand Blvd, Detroit, MI 48202, USA patients and are eight times more likely to die than other patients [2,6]. Early aggressive treatment for sepsis increases the chances for survival [7]. Tenets of aggressive treatment include early antibiotic therapy [8] and aggressive resuscitative strategies to achieve monitored clinical goals [9].

Patients with sepsis are a heterogeneous group with various predisposing features and sources of infection. Patients who are critically ill from all causes have a higher mortality when they have cardiac dysfunction [10]. Sepsis may be associated with concurrent reversible left ventricular dysfunction (LVD) [11] that some authors have attributed to circulating factors [2,12]. Patients with LVD that occurs during sepsis may have a worse prognosis than patients who do not have this condition [12,13]. 
Cardiac disease has a high prevalence in hospitalized patients [14], which may complicate the management of sepsis. However, the outcomes for septic patients who have pre-existing LVD have not been carefully studied.

Early sepsis management requires aggressive fluid resuscitation to defined clinical endpoints, whereas it may be necessary to be more circumspect in the administration of fluids in later phases of sepsis [15]. The presence of LVD in critically ill septic patients complicates this strategy and leads to concerns about the development of pulmonary edema and respiratory failure from excessive fluid resuscitation. Alterations in the cardiac compliance in patients with LVD may diminish the utility of the central venous pressure as a preload assessment tool [16]. Both the mixed venous oxygen saturation $\left(\mathrm{ScVO}_{2}\right)$ and the serum lactate level may be affected by the presence of LVD as well as sepsis, potentially confounding their utility in patients with both disorders [17-19]. More data are needed to guide clinicians in the management of these difficult patients.

Our institution has maintained an extensive database since 2005 for all hospitalized patients treated for sepsis. We selected a population of patients with both acute sepsis and prior evidence of LVD for this study. In order to determine if differences exist between septic patients with pre-existing LVD and those without, we selected case-matched control patients with normal pre-sepsis LV function for comparison purposes. We chose to analyze clinical parameters of both case and control patients in order to identify risk factors for in-hospital mortality. The identification of differences between septic patients with and without pre-existing LVD, and the ascertainment of sepsis mortality risk factors in each group, may lead to the refinement of management algorithms in the subpopulation of patients with pre-existing LVD.

\section{Materials and methods Study design and enrollment}

All patients at our institution who developed sepsis after January 2005 had medical data entered into an institutional sepsis quality improvement database. Patients admitted to the Emergency Department, hospital wards or intensive care units with a diagnosis of sepsis, as well as those who developed sepsis during the course of their hospital stay for another diagnosis, were included in the database. We retrospectively reviewed data collected between 1 January 2005 and 30 June 2010. We additionally examined data from the institutional electronic medical record (EMR) of all patients enrolled in the sepsis database. The study was performed at a quaternary health care system located in the midwestern United States. The study protocol was ethically reviewed and approved by the Henry Ford Health Systems Institutional Review Board (IRB project number 6237; Henry Ford Health
Systems Institutional Review Board). The need for informed consent was waived by the Henry Ford Health Systems Review Board because the study was an observational non-interventional retrospective study using a database where patient identification information had been removed.

Case subjects were identified as those patients entered into the sepsis database that had an echocardiogram performed and entered into the EMR prior to (but not more than two years before) the incidence of sepsis with a reported left ventricular ejection fraction (LVEF) of $50 \%$ or less. When patients had multiple echocardiograms reported in the EMR prior to the sepsis event, we used the results from the echocardiogram performed most proximate to the event. Each case subject had the diagnosis of sepsis confirmed by retrospective review of the EMR. If a potential case subject had multiple admissions entered into the database, only the first admission was considered for study purposes. Potential case subjects were excluded if they were receiving renal replacement therapy prior to the sepsis event. These patients were excluded because the physiologic factors associated with end-stage renal disease and its management could confound the analysis of the effects of left ventricular dysfunction in patients with sepsis. Patients with any degree of renal insufficiency not requiring renal replacement therapy (including patients who had received a kidney transplant), or who developed a need for renal replacement therapy while being treated for sepsis, were included in the study if they met enrollment criteria.

Control subjects were chosen from the database for each case subject in a 1:1 ratio by selecting from age- and gender-matched patients with an LVEF greater than 50\% by echocardiogram (not concurrent but within two years of the sepsis event). The potential control subject with a date of birth closest to the case subject was selected. Potential control subjects were excluded if they had cardiac wall motion abnormalities, valvular cardiac abnormalities, significant evidence of diastolic dysfunction on echocardiogram, or had any evidence of an acute cardiac ischemic syndrome during their hospitalization for sepsis. Control subjects were otherwise required to meet the same inclusion criteria as case subjects. The information for each study subject was entered into a research database without patient identifiers for analysis.

\section{Definitions}

"Sepsis" was defined as being present if a patient manifested at least two of four systemic inflammatory response syndrome criteria and had documented evidence of infection. "LVEF" was defined as the estimated fractional diminution in size of the left ventricular cavity during systole as reported in standard echocardiographic interpretations. When a range was provided in a report for LVEF, the midpoint of that range was chosen as the 
LVEF for study purposes. "Sepsis bundle" was defined as the algorithm used for sepsis management described by Rivers and co-workers [9]. "Compliance with the sepsis bundle" was defined as being present when the patient was treated completely in accordance with the sepsis bundle. The patient was not compliant with the sepsis bundle if any parameter of the sepsis bundle was not met. "Time 0 " was defined as the point in time when the sepsis bundle was initiated for each study subject. "Intubation" was defined as endotracheal intubation and mechanical ventilation within 24 hours of Time 0.

\section{Statistical analysis}

We performed all statistical analysis using SPSS software version 18 with a logistical regression add-on package version 20 (International Business Machines, Armonk, New York, United States of America) and considered $P<0.05$ to be statistically significant unless otherwise specified. We used chi-squared tests, two-sample $t$ tests, or MannWhitney $U$ tests as appropriate for univariable analysis. Adjustments were not made for multiple comparisons.

For both case and control subjects, we analyzed the relationship between the dependent variable $\mathrm{PaO}_{2} / \mathrm{FiO}_{2}$ at 24 hours and the total intravenous fluid volume administered over 24 hours using linear regression analysis. Results are displayed as scatter plots and the goodness of fit is indicated by $\mathrm{r}^{2}$.

Cases and controls were matched for age and gender. We used multivariable logistic regression analysis with mortality as the dependent variable to additionally control for the effects of $\mathrm{ScVO}_{2}$, hematocrit, lactate levels and intubation status on the association of mortality between cases and controls.

We developed a model to identify risk factors for mortality by multivariable logistic regression analysis in both the case and control subject populations. Potential risk factors were identified from a univariable analysis of each of the available variables using mortality as the dependent variable. Variables were selected for analysis if they were significantly associated with mortality $(P<0.1)$ and if at least $80 \%$ of the case and control subjects had data available for the variable. A correlation matrix was constructed for the continuous independent variables in the case and control subject populations and the variables were examined for collinearity by Pearson's correlation.

\section{Results}

Clinical data were collected in a quality improvement database at our institution for 1,717 hospitalized patient episodes with a diagnosis of sepsis between 1 January 2005 and 30 June 2010. Of these patients, 510 died during their hospital stay, while 1,207 survived until discharge, for an in-hospital all-cause mortality rate of $29.7 \%$. We identified 197 study subjects who met inclusion criteria and had both sepsis and pre-existing LVD. We chose 197 control subjects with normal left ventricular function from the quality improvement database matched to cases according to age and gender. Comparisons between the mean values for various clinical variables for cases and controls are presented in Table 1. Comparisons of clinical outcomes for cases and controls are presented in Table 2. When controlled for $\mathrm{ScVO}_{2}$, hematocrit, lactate levels and intubation status by multivariable logistic regression analysis using mortality as the dependent variable, the mortality risk between cases and controls was not different $(P=0.183$, OR $=1.41)$. The other risk factors studied, $\mathrm{ScVO}_{2}(P=0.005, \mathrm{OR}=0.998)$, intubation $(P=0.000$, $\mathrm{OR}=2.56)$, hematocrit $(P=0.012, \mathrm{OR}=0.996)$ and initial lactate level $(P=0.037, \mathrm{OR}=1.078)$ were all significantly associated with mortality.

In order to study the effect of the administration of intravenous fluid volume on respiratory gas exchange, we examined the relationship between the total intravenous fluid volume administered during the first 24 hours of patient admission with the ratio of the partial pressure of oxygen to the fraction of inspired oxygen $\left(\mathrm{PO}_{2} / \mathrm{FiO}_{2}\right)$ obtained at 24 hours by linear regression analysis in both cases and controls. Data for the volume of fluid administered were available for most patients $(n=190$ for cases; $\mathrm{n}=192$ for controls), but the data availability for the $\mathrm{PO}_{2} / \mathrm{FiO}_{2}$ at 24 hours was more limited $(\mathrm{n}=108$ for cases; $\mathrm{n}=115$ for controls). We found no relationship between intravenous fluid volume and the $\mathrm{PO}_{2} / \mathrm{FiO}_{2}$ at 24 hours in either cases or controls $\left(r^{2}=0.019\right.$ for cases, $r^{2}=0.001$ for controls; Figures 1 and 2).

We examined the population of patients with preexisting LVD to determine if there were differences between those subjects with more severe LVD compared to those subjects with less severe dysfunction other than the reduction in LVEF. There were 81 patients with an LVEF of less than $35 \%$, compared to 116 patients with an LVEF greater than or equal to $35 \%$ but less than $50 \%$. Patients with an LVEF less than 35\% received less intravenous fluid during their resuscitation than did patients with a higher LVEF $(3.40+/-2.07 \mathrm{~L}$ compared with $4.42+/-3.09 \mathrm{~L}, P=0.012)$. However, mortality rate $(27 \%$ versus $35 \%, P>0.05)$, intubation rate ( $47 \%$ versus $43 \%$, $P>0.05)$, use of vasopressors ( $46 \%$ versus $44 \%, P>0.05$ ), Acute Physiology and Chronic Health Evaluation II (APACHE II) score $(20+/-7$ versus $19+/-6, P=0.285)$, ScVO2 $(67.9+/-16.0 \%$ versus $66.0+/-17.1 \%, P=0.472)$, and initial lactate levels $(3.8+/-3.7 \mathrm{mmol} / \mathrm{L}$ versus $3.1+/-2.5 \mathrm{mmol} / \mathrm{L}$, $P=0.121$ ) were not statistically different between patients with an LVEF of less than 35\% and those with an LVEF between $35 \%$ and $50 \%$.

We studied both the case and the control populations to determine the risk factors for mortality in each group. We applied univariable analysis of 25 potential risk factors 
Table 1 Comparisons of clinical variables between cases and controls

\begin{tabular}{|c|c|c|c|}
\hline Variable & Cases (n) & Controls $(n)$ & $P$ \\
\hline Age (years) & $68+/-16(197)$ & $67+/-16(197)$ & $0.935^{b}$ \\
\hline Male gender & $129(197)$ & $129(197)$ & $1.000^{\mathrm{a}}$ \\
\hline $\operatorname{LVEF}(\%)$ & $35+/-12(197)$ & $60+/-5(197)$ & $<0.001^{\mathrm{b}}$ \\
\hline APACHE $\|$ & $20+/-7(194)$ & $19+/-8(191)$ & $0.603^{b}$ \\
\hline Initial CVP $\left(\mathrm{cm} \mathrm{H}_{2} \mathrm{O}\right)$ & $9+/-8(128)$ & $8+/-7(120)$ & $0.334^{b}$ \\
\hline $\mathrm{ScVO}_{2}(\%)$ & $67+/-17(166)$ & $71+/-16(166)$ & $0.009^{b}$ \\
\hline Lung Infection & $64(197)$ & $54(197)$ & $0.322^{\mathrm{a}}$ \\
\hline Sepsis bundle compliant & $61(197)$ & $69(197)$ & $0.453^{\mathrm{a}}$ \\
\hline MAP $<65 \mathrm{~mm} \mathrm{Hg}$ & $116(197)$ & $114(197)$ & $0.919^{a}$ \\
\hline Initial temperature $\left({ }^{\circ} \mathrm{C}\right)$ & $36.9+/-1.6(196)$ & $37.0+/-1.5(195)$ & $0.714^{\mathrm{b}}$ \\
\hline Temperature at 24 hours $\left({ }^{\circ} \mathrm{C}\right)$ & $37.2+/-2.0(197)$ & $37.3+/-2.0(197)$ & $0.471^{b}$ \\
\hline Initial heart rate $\left(\mathrm{min}^{-1}\right)$ & $104+/-27(197)$ & $108+/-24(197)$ & $0.074^{b}$ \\
\hline Heart rate at 24 hours $\left(\mathrm{min}^{-1}\right)$ & $115+/-32(197)$ & $117+/-29(197)$ & $0.360^{\mathrm{b}}$ \\
\hline Initial respiratory rate $\left(\mathrm{min}^{-1}\right)$ & $24+/-9(197)$ & $24+/-9(197)$ & $0.558^{b}$ \\
\hline Respiratory rate at 24 hours $\left(\mathrm{min}^{-1}\right)$ & $29+/-9(197)$ & $30+/-9(197)$ & $0.435^{b}$ \\
\hline Initial MAP $(\mathrm{mm} \mathrm{Hg})$ & $74+/-22(197)$ & $76+/-23(197)$ & $0.502^{b}$ \\
\hline MAP at 24 hours (mm Hg) & $58+/-19(197)$ & $60+/-21(197)$ & $0.226^{b}$ \\
\hline Initial pH & $7.35+/-0.12(176)$ & $7.35+/-0.13(175)$ & $0.994^{b}$ \\
\hline $\mathrm{pH}$ at 24 hours & $7.31+/-0.13(112)$ & $7.29+/-0.15(107)$ & $0.302^{b}$ \\
\hline Initial $\mathrm{PO}_{2} / \mathrm{FiO}_{2}$ & $259+/-130(161)$ & $266+/-139(166)$ & $0.630^{b}$ \\
\hline $\mathrm{PO}_{2} / \mathrm{FiO}_{2}$ at 24 hours & $265+/-113(108)$ & $268+/-126(115)$ & $0.846^{b}$ \\
\hline Initial sodium (mg/dL) & $139+/-7(196)$ & $139+/-12(197)$ & $0.730^{b}$ \\
\hline Initial creatinine (mg/dL) & $3.04+/-2.72(195)$ & $2.73+/-3.28(197)$ & $0.115^{c}$ \\
\hline Initial hematocrit (\%) & $31.6+/-6.6(197)$ & $33.1+/-8.1(197)$ & $0.046^{\mathrm{b}}$ \\
\hline Initial WBC (x10 ul) & $15.1+/-9.7(196)$ & $16.4+/-15.6(197)$ & $0.294^{b}$ \\
\hline Initial platelet count ( $\times 10^{3} \mathrm{ul}$ ) & $234+/-138(195)$ & $231+/-153(196)$ & $0.844^{b}$ \\
\hline Initial lactate $(\mathrm{mmol} / \mathrm{L})$ & $3.4+/-3.0(196)$ & $4.1+/-3.5(195)$ & $0.019^{c}$ \\
\hline Initial glucose (mg/dL) & $136+/-98(197)$ & $136+/-52(197)$ & $0.960^{b}$ \\
\hline Initial 24-hour fluid volume (ml) & $4,005+/-2,763(190)$ & $4,378+/-3,040(192)$ & $0.321^{c}$ \\
\hline Receipt of vasoactive agents & $88(197)$ & $79(197)$ & $0.415^{\mathrm{a}}$ \\
\hline
\end{tabular}

Significance, $\mathrm{P}<0.05 ;{ }^{\mathrm{a} C h i}$-square test; ${ }^{\mathrm{b}}$ Student's $t$-test; ${ }^{\mathrm{C}}$ Mann-Whitney U test. APACHE II, Acute Physiology and Chronic Health Evaluation II; CVP, central venous pressure; LVEF, left ventricular ejection fraction; MAP, mean arterial pressure; $\mathrm{PO}_{2} / \mathrm{FiO}_{2}$, partial pressure of oxygen to the fraction of inspired oxygen; $\mathrm{ScVO}_{2}$, mixed venous oxygen saturation; WBC, white blood count.

Table 2 Comparison of clinical outcomes between cases and controls

\begin{tabular}{llll}
\hline Variable & Cases (n) & Controls (n) & $P$ \\
\hline $\begin{array}{l}\text { MAP }>65 \mathrm{~mm} \mathrm{Hg} \text { following } \\
\text { fluid resuscitation }\end{array}$ & $101(197)$ & $114(197)$ & 0.225 \\
$\begin{array}{l}\text { MAP }>65 \mathrm{~mm} \text { Hg following receipt } \\
\text { of vasoactive agents for hypotension }\end{array}$ & $74(85)$ & $64(75)$ & 0.532 \\
$\begin{array}{l}\text { Initiation of dialysis } \\
\text { Intubated }\end{array}$ & $2(197)$ & $1(197)$ & 1.000 \\
Mortality & $93(197)$ & $98(197)$ & 0.687 \\
\hline
\end{tabular}

Chi-square test used for dichotomous variables. MAP, mean arterial pressure. with mortality as the dependent variable to both the cases and control groups. Results are presented in Table 3. Significant correlations by Pearson's correlation were demonstrated in both populations between the APACHE II score and the lactate level $(P=0.001)$. We chose to exclude APACHE II from the multivariable model. We also found a significant correlation between the hematocrit and respiratory rate in the case but not the control subjects ( $P=0.003$ for the cases, $P=0.210$ for the controls). We chose to exclude respiratory rate from the model as well. The model used for the multivariable logistic regression analysis, with mortality as the dependent variable, and which was applied to the case and control population 


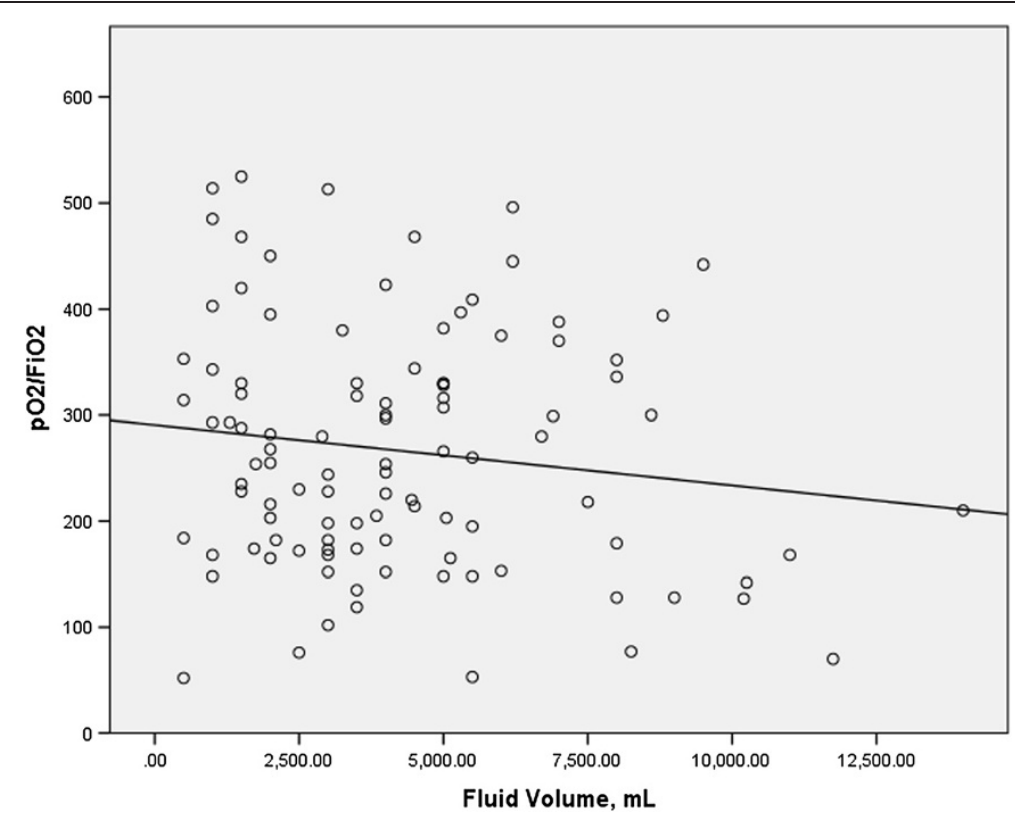

Figure 1 Intravenous fluid volume over the initial 24 hours versus PO2/FiO2 at 24 hours for cases. $r^{2}=0.019$.

in turn, included the following covariates: intubation status, $\mathrm{ScVO}_{2}$, initial hematocrit, initial platelet count, compliance with a sepsis bundle, lung infection, serum lactate level and the use of vasoactive agents to augment blood pressure. The results of this analysis are presented in Table 4. Risk factors for mortality were different between cases and controls. Significant risk factors for mortality among patients with pre-existing left ventricular dysfunction included the $\mathrm{ScVO}_{2}$, compliance with a sepsis algorithm, intubation status and a source of infection other than the lung. Significant risk factors for mortality among patients with pre-existing normal left ventricular function included the initial platelet count and the initial lactate level. While the $\mathrm{ScVO}_{2}$ was similar between survivors and non-survivors among control patients, the $\mathrm{ScVO}_{2}$ was significantly lower among non-surviving patients with pre-existing LVD compared with surviving patients (Table 5).

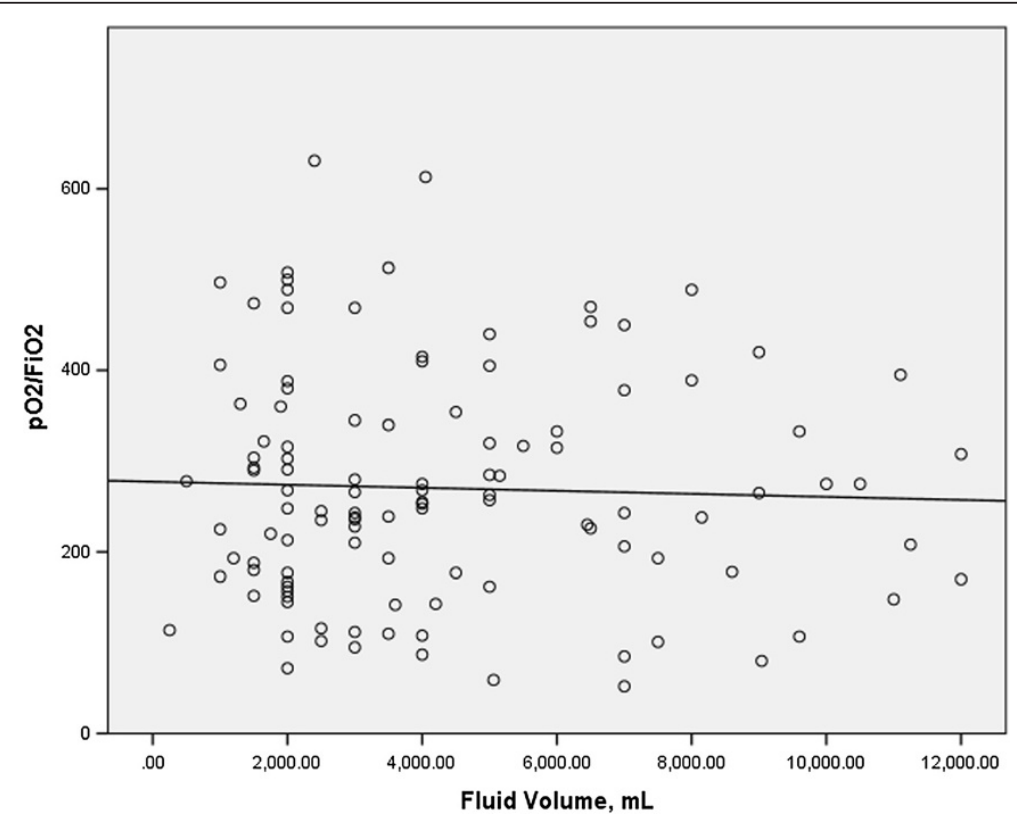

Figure 2 Intravenous fluid volume over the initial 24 hours versus $\mathrm{PO}_{2} / \mathrm{FiO}_{2}$ at 24 hours for controls. $\mathrm{r}^{2}=0.001$. 
Table 3 Risk factors for mortality among cases and controls by univariable analysis

\begin{tabular}{|c|c|c|}
\hline Risk factors & $P$, cases $(\mathrm{n})$ & $P$, controls $(\mathrm{n})$ \\
\hline Age & $0.122(197)$ & $0.199(197)$ \\
\hline Initial CVP & $0.232(128)$ & $0.731(120)$ \\
\hline Initial temperature & $0.210(196)$ & $0.243(195)$ \\
\hline Initial heart rate & $0.792(197)$ & $0.885(197)$ \\
\hline Initial respiratory rate & $0.626(197)$ & $\mathbf{0 . 0 1}(197)^{*}$ \\
\hline Initial MAP & $0.792(197)$ & $0.636(197)$ \\
\hline Initial $\mathrm{PO}_{2} / \mathrm{FiO}_{2}$ & $0.254(161)$ & $0.267(166)$ \\
\hline $\mathrm{PO}_{2} / \mathrm{FiO}_{2}$ at 24 hours & $0.155(108)$ & $0.013(115)^{*}$ \\
\hline Initial pH & $0.374(176)$ & $0.432(175)$ \\
\hline $\mathrm{pH}$ at 24 hours & $0.001(112)^{*}$ & $0.028(107)^{*}$ \\
\hline Initial creatinine & $0.166(195)$ & $0.466(197)$ \\
\hline Initial hematocrit & $\mathbf{0 . 0 7 4}(197)^{*}$ & $0.071(197)^{*}$ \\
\hline Initial WBC & $0.619(196)$ & $0.672(197)$ \\
\hline Initial platelet & $0.974(195)$ & $0.055(196)^{*}$ \\
\hline APACHE ॥ & $0.028(194)^{*}$ & $0.007(191)^{*}$ \\
\hline Initial lactate & $0.008(196)^{*}$ & $0.019(195)^{*}$ \\
\hline 24-hour fluid volume & $0.576190)$ & $0.747(192)$ \\
\hline $\mathrm{ScVO}_{2}$ & $0.002(166)^{*}$ & $0.882(168)$ \\
\hline Glucose level & $0.717(197)$ & $0.136(197)$ \\
\hline No vasoactive drug use & $0.016(197)^{\#}$ & $0.009(197)^{\#}$ \\
\hline No Intubation & $\mathbf{0 . 0 0 1}(197)^{\#}$ & $0.007(197)^{\#}$ \\
\hline LVEF & $0.236(197)$ & $0.319(197)$ \\
\hline Fail bundle compliance & $0.002(197)^{\#}$ & $0.328(197)$ \\
\hline Gender & $0.811(197)$ & $0.880(197)$ \\
\hline Source other than lung & $0.006(197)^{\#}$ & $0.754(197)$ \\
\hline
\end{tabular}

Student's $t$-test ${ }^{*}$ and Chi Square ${ }^{\# ;} P<0.1$ significant. APACHE II, Acute Physiology and Chronic Health Evaluation II; CVP, central venous pressure; LVEF, left ventricular ejection fraction; MAP, mean arterial pressure; $\mathrm{PO}_{2} / \mathrm{FiO}_{2}$, partial pressure of oxygen to the fraction of inspired oxygen; $\mathrm{ScVO}_{2}$, mixed venous oxygen saturation; WBC, white blood count.

\section{Discussion}

To our knowledge, this is the first study to compare patients with sepsis and pre-existing LVD to patients with sepsis with no significant pre-existing cardiac abnormalities. We found that septic patients with pre-existing LVD differed only modestly from patients with preserved left ventricular function at our institution. Both populations had similar degrees of severity of illness, as assessed by the APACHE II score. Although patients with pre-existing LVD had significantly lower $\mathrm{ScVO}_{2}$ values, hematocrit levels and initial lactate levels than did patients with normal pre-sepsis ventricular function, other demographic and laboratory determinants were similar. Important clinical outcomes, such as in-hospital mortality and intubation rates, were not significantly different between the two groups of patients, though there was a trend towards increased mortality in the patients with pre-existing LVD.

Fluid management in critically ill patients with sepsis is complex, in part because the clinical endpoints for fluid administration change during the course of the septic episode. Initially, there is a general consensus that fluid administration should be liberal and aggressive $[5,9]$. Clinical management during the initial 24 hours of therapy emphasize the use of resuscitation goals that implicate sufficient tissue delivery of oxygen and include not only traditional hemodynamic measurements and urine output but also variables related to oxygen delivery and consumption, such as hemoglobin and mixed venous oxygen saturation. Subsequently, however, patient outcomes are improved in critically ill septic patients by observing conservative fluid management strategies [20]. The supporting rationale for the application of conservative fluid management strategies during the late stages of sepsis stem from observations of improved patient outcomes from the use of such strategies for the treatment of acute lung injury [21,22]. Complex patients with both pre-existing LVD and sepsis might be perceived as being more susceptible than other septic patients to developing respiratory complications from aggressive initial fluid resuscitation because pulmonary edema is a component of the congestive heart failure

Table 4 Risk factors for mortality among cases and controls by multivariable logistic regression analysis

\begin{tabular}{lllll}
\hline Risk factors & $\boldsymbol{P}$, cases & Odds ratio, cases & $\boldsymbol{P}$, controls & Odds ratio, controls \\
\hline No intubation & $\mathbf{0 . 0 1 6 ^ { * }}$ & 0.356 & 0.081 & 0.474 \\
Initial hematocrit & 0.148 & 0.996 & 0.091 & 0.996 \\
Initial platelet & 0.700 & 0.999 & $\mathbf{0 . 0 2 8 ^ { * }}$ & 0.997 \\
Fail bundle compliance & $\mathbf{0 . 0 0 8 ^ { * }}$ & 3.516 & 0.760 & 0.872 \\
Source other than lung & $\mathbf{0 . 0 1 9 ^ { * }}$ & 2.782 & 0.539 & 0.773 \\
Initial lactate & 0.490 & 1.040 & $\mathbf{0 . 0 4 8 ^ { * }}$ & 1.104 \\
No vasopressors & 0.641 & 1.228 & 0.071 & 0.463 \\
$\mathrm{ScVO}_{2}$ & $\mathbf{0 . 0 0 4 ^ { * }}$ & 0.997 & 0.239 & 0.999 \\
\hline
\end{tabular}

$P<0.05$ is significant* $\mathrm{ScVO}_{2}$, mixed venous oxygen saturation. 
Table 5 Comparison of initial mean $\mathrm{ScVO}_{2}$ between survivors and non-survivors, cases and controls

\begin{tabular}{llll}
\hline Group & $\mathbf{n}$ & $\mathrm{ScVO}_{\mathbf{2}}(\%)$ & $\boldsymbol{P}$ \\
\hline Non-survivors, cases & 57 & $61+/-17$ & \\
Survivors, cases & 109 & $70+/-16$ & $0.002^{\mathrm{a}}$ \\
Non-survivors, controls & 44 & $71+/-15$ & \\
Survivors, controls & 124 & $72+/-16$ & $0.882^{\mathrm{b}}$ \\
\hline
\end{tabular}

${ }^{a}$ Comparison of means by Student's $t$-test, non-survivors and survivors, cases. ${ }^{b}$ Comparison of means by Student's $t$-test, non-survivors and survivors, controls. $\mathrm{ScVO}_{2}$, mixed venous oxygen saturation.

syndrome. Although patients with an LVEF below 35\% did not have a different severity of illness nor different outcomes than patients with LVD but with higher LVEF, they did receive statistically less intravenous fluid during this resuscitation. We speculate that this may reflect practice patterns directed by the assumption just noted. We observed that patients with both sepsis and preexisting LVD were no more likely to be intubated and require mechanical ventilation than case-matched controls, although the need for intubation was a mortality risk factor in these patients. Additionally, we found no correlation between the amount of resuscitative fluid administered over the first 24 hours and oxygenation in that group of cases and controls for whom data were available. We suggest that patients with sepsis and pre-existing LVD may be no more likely than other patients to develop respiratory compromise from goal-directed volume resuscitation in early sepsis.

Studies involving animal models over 40 years ago demonstrated that serum lactate levels were elevated when tissue oxygenation was decreased by experimental manipulation of the determinants of oxygen delivery $[23,24]$. Increased lactate levels have been demonstrated to be associated with poor outcomes in critically ill patients [25], patients with circulatory shock [26], and patients with severe sepsis [27]. Production of lactate appears to be increased both in patients with circulatory shock and sepsis, though the putative mechanisms may be different: in circulatory shock mechanisms implicating oxygen delivery play an important role, whereas in sepsis constitutive cellular mechanisms of lactate production are prominent [28]. While there are some data that suggest that lactate clearance may be preserved in circulatory shock [29], lactate clearance seems to be diminished in some patients with sepsis [30]. We observed that the mean initial lactate level for patients who had sepsis and pre-existing LVD was less than that of the control group in our study, though the mean lactate levels for both groups were elevated compared to normal values. Initial lactate levels were closely associated with mortality in our septic control patients, but not in our septic patients with pre-existing LVD. The reasons for these findings are not clear, but may be related to the complex interaction of multiple factors effecting lactate metabolism in patients with multi-system disease. We suggest that initial serum lactate levels may be less important a predictor of outcome in septic patients with pre-existing LVD than they are in other septic patients.

Kasnitz and co-workers studied the relationship between $\mathrm{ScVO}_{2}$ and lactate levels in patients with cardiopulmonary disease, noting that $\mathrm{ScVO}_{2}$ levels were decreased in such patients and associated with increased lactate levels and mortality [17]. The presumed mechanism for this phenomenon is that diminished cardiac output leads to decreased oxygen delivery to tissues, increased oxygen extraction and, therefore, diminished oxygen saturation in blood returning to the heart [31]. In a large cohort of patients undergoing coronary artery bypass graft surgery, a threshold value for $\mathrm{ScVO}_{2}$ less than $60.1 \%$ was identified below which mortality was increased [32]. In contrast to the findings in patients with cardiogenic shock, early work suggested that $\mathrm{ScVO}_{2}$ was normal or increased in patients with septic shock [33]. Mechanistically, it has been suggested that this phenomenon occurs because of decreased oxygen extraction and utilization. Krafft and co-workers provided evidence supporting this hypothesis in general, but suggested that short-term decrements in $\mathrm{ScVO}_{2}$ might be associated with adverse clinical outcomes [34]. More recently, Rivers and associates demonstrated that a strategy that, in part, targets augmenting $\mathrm{ScVO}_{2}$ in septic patients leads to improved clinical outcomes [9]. However, the control group in the latter study had a mean $\mathrm{ScVO}_{2}$ of $49 \%$, which is different from that expected from prior work. Concerns have been raised about the ability to generalize the findings of Rivers et al. given that most septic populations have $\mathrm{ScVO}_{2}$ levels in the normal or supranormal range [35].

We found that patients with pre-existing LVD and sepsis had a lower mean initial $\mathrm{ScVO}_{2}$ than a control group of septic patients, a finding which is supported by previous work [36]. Patients with pre-existing LVD in our study who died had a significantly lower $\mathrm{ScVO}_{2}$ than survivors, and low $\mathrm{ScVO}_{2}$ was an independent risk factor for mortality. These findings were not observed in the control cohort. The additional observation that failure to comply with a protocol targeted to improve oxygen delivery variables was an independent risk factor for mortality in cases, but not controls, suggests to us that patients with pre-existing LVD may have a different physiological response profile during sepsis than other septic patients. We postulate that sepsis is a heterogeneous disorder, and management strategies that target oxygen delivery variables may be particularly appropriate for patients with pre-existing LVD.

Our work suffers from a number of important limitations. This study is from a single center, which may limit the applicability of the results. We retrospectively reviewed 
a quality improvement database; so that there is a risk that unappreciated confounding variables may be present. We did not assess left ventricular function systematically during the sepsis event in any patients, leading to the possibility that controls or cases may have had unrecognized synchronous LVD. The number of patients included in our study was relatively small, limiting the strength of our conclusions. Larger, prospective studies will need to be performed to confirm our findings.

\section{Conclusions}

This single center retrospective study demonstrates that patients with sepsis and pre-existing LVD may have similar outcomes when compared to patients with sepsis without pre-existing LVD. No correlation was demonstrated between the amount of intravenous fluid administered over the first 24 hours and oxygenation at 24 hours in septic patients either with or without pre-existing LVD. Mortality risk factors for patients with pre-existing LVD and sepsis included a low $\mathrm{ScVO}_{2}$, failure to comply with a sepsis bundle of therapies, intubation status, and a source of infection other than the lung, whereas mortality risk factors for septic patients with no previous evidence of cardiac disease included increased lactate levels and a low platelet count. Further study will be needed to determine if improvement of oxygen delivery during sepsis is more important in ameliorating outcome in patients with pre-existing LVD compared to those without.

\section{Key messages}

- Patients with sepsis and pre-existing left ventricular dysfunction have similar outcomes when compared to patients with sepsis with normal pre-existing left ventricular function.

- Patients with pre-existing left ventricular dysfunction who suffer from sepsis may be no more likely than patients with normal left ventricular function and sepsis to develop respiratory compromise when treated aggressively with intravenous fluids.

- Patients with pre-existing left ventricular dysfunction who develop sepsis have different mortality risk factors than other patients. Mortality risk factors are related to oxygen delivery variables in these patients.

\begin{abstract}
Abbreviations
APACHE II: Acute Physiology and Chronic Health Evaluation II; CVP: Central venous pressure; EMR: Electronic medical record; LVD: Left ventricular dysfunction; LVEF: Left ventricular ejection fraction; OR: Odds ratio; $\mathrm{PO}_{2} /$ $\mathrm{FiO}_{2}$ : Partial pressure of oxygen/Fraction of inspired oxygen; $\mathrm{ScVO}_{2}$ : Mixed venous oxygen saturation; WBC: white blood count.
\end{abstract}

\section{Competing interests}

Both authors are salaried employees of Henry Ford Health Systems in Detroit, MI, USA. Henry Ford Health System patients and infrastructure were utilized in this research, and the health care system may benefit from an enhanced reputation by the publication of this article. Henry Ford Health System may pay publishing costs of this work. The authors have no other competing interests to declare.

\section{Authors' contributions}

Both DRO and SS made substantial contributions to the study's conception and design, were involved in acquiring data, and participated in analyzing and interpreting the data. Both DRO and SS were involved in writing and revising the manuscript in terms of important intellectual content. Both DRO and SS have given approval for manuscript publication. Both authors read and approved the final manuscript.

\section{Authors' information}

DRO is a Senior Staff Physician in the Pulmonary and Critical Care Medicine Division at Henry Ford Hospital and is an Associate Professor of Medicine at Wayne State University School of Medicine. SS is a Fellow in Pulmonary and Critical Care Medicine at Henry Ford Hospital.

\section{Acknowledgements}

Dr. John Ward, a statistician at Henry Ford Hospital, reviewed the statistical methods for this study.

Dr. Lenar Yessayan, a nephrologist and critical care physician at Henry Ford Hospital, reviewed the statistical methods for this study.

No intramural or extramural funding was received for this study.

Received: 6 October 2013 Accepted: 11 March 2014

Published: 23 April 2014

\section{References}

1. Angus DC, Linde-Zwirble WT, Lidicker J, Clermont G, Carcillo J, Pinsky MR: Epidemiology of severe sepsis in the United States: analysis of incidence, outcome, and associated costs of care. Crit Care Med 2001, 29:1303-1310.

2. Hall JH, Williams SN, DeFrances CJ, Golosinsky A: Inpatient Care for septicemia or sepsis: A challenge for patients and hospitals. NCHS Data Brief No. 62, 2011. [http://www.cdc.gov/nchs/data/databriefs/db62.htm]

3. Lagu T, Rothberg MB, Shieh M-S, Pekow PS, Steingrub JS, Lindenauer PK: Hospitalizations, costs, and outcomes of severe sepsis in the United States 2003 to 2007. Crit Care Med 2012, 40:754-761.

4. Iwashyna TJ, Ely EW, Smith DM, Langa KM: Long-term cognitive impairment and functional disability among survivors of severe sepsis. JAMA 2010, 304:1787-1793.

5. Agency for Healthcare Research and Quality: HCUP facts and figures: statistics on hospital-based care in the United States, 2008. [http://www.hcup-us.ahrq.gov/reports/factsandfigures/2008/TOC_2008.jsp]

6. Hall MJ, DeFrances CJ, Williams SN, Golosinsky A, Schwartzman A: National hospital discharge survey: 2007 summary. National Health Statistics Reports, No. 29, 2010. [http://www.cdc.gov/nchs/data/nhsr/nhsr029.pdf]

7. Dellinger RP, Levy MM, Rhodes A, Annane D, Gerlach H, Opal SM, Sevransky JE, Sprung CL, Douglas IS, Jaeschke R, Osborn TM, Nunnally ME, Townsend SR, Reinhart K, Kleinpell RM, Angus DC, Deutschman CS, Machado FR, Rubenfeld GD, Webb SA, Beale RJ, Vincent J-L, Moreno R, Surviving Sepsis Campaign Guidelines Committee including the Pediatric Subgroup: Surviving sepsis campaign: International guidelines for management of severe sepsis and septic shock: 2012. Crit Care Med 2013, 41:580-637.

8. Kumar A, Roberts D, Wood KE, Light B, Parillo JE, Sharma S, Suppes R, Feinstein D, Zanotti S, Taiberg L, Gurka D, Kumar A, Cheang M: Duration of hypotension before initiation of effective antimicrobial therapy is the critical determinant of survival in human septic shock. Crit Care Med 2006, 34:1589-1596.

9. Rivers E, Nguyen B, Havstad S, Ressler J, Muzzin A, Knoblich B, Peterson E, Tomlanovich M, Early Goal-Directed Therapy Collaborative Group: Early goal-directed therapy in the treatment of severe sepsis and septic shock. N Engl J Med 2001, 345:1368-1377.

10. Kollef MH, Ladenson JH, Eisenberg PR: Clinically recognized cardiac dysfunction: an independent determinant of mortality among critically ill patients. Chest 1997, 111:1340-1347.

11. Parker MM, Shelhamer JH, Bacharach SL, Green MV, Natanson C, Frederick TM, Damske BA, Parrillo JE: Profound but reversible myocardial depression in patients with septic shock. Ann Intern Med 1984, 100:483-490.

12. Maeder M, Fehr T, Rickli H, Ammann P: Sepsis-associated myocardial dysfunction. Chest 2006, 129:1349-1366. 
13. Poelaert J, Declerck C, Vogelaers D, Colardyn F, Visser CA: Left ventricular dysfunction and diastolic dysfunction in septic shock. Intensive Care Med 1997, 23:553-560.

14. Roger VL, Go AS, Lloyd-Jones DM, Adams RJ, Berry JD, Brown TM, Carnethon MR, Dai S, de Simone G, Ford ES, Fox CS, Fullerton HJ, Gillespie C, Greenlund KJ, Hailpern SM, Heit JA, Ho PM, Howard VJ, Kissela BM, Kittner SJ, Lackland DT, Lichtman JH, Lisabeth LD, Makuc DM, Marcus GM, Marelli A, Matchar DB, McDermott MM, Meigs JB, Moy CS, et al: Heart disease and stroke statistics 2011 update: a report from the American Heart Association. Circulation 2011, 123:e18-e209.

15. Durairaj $L$, Schmidt GA: Fluid therapy in resuscitated sepsis: less is more. Chest 2008, 133:252-263.

16. Forrester JS, Diamond G, McHugh TJ, Swan HJ: Filling pressure in the right and left sides of the heart in acute myocardial infarction. $N$ Engl J Med 1971, 285:190-193.

17. Kasnitz P, Druger GL, Yorra F, Simmons DH: Mixed venous oxygen tension and hyperlactatemia: survival in severe cardiopulmonary disease. JAMA 1976, 236:570-574.

18. Howell MD, Donnino M, Clardy P, Talmor D, Shapiro NI: Occult hypoperfusion and mortality in patients with suspected infection. Intensive Care Med 2007, 33:1892-1899.

19. Casserly B, Read R, Levy MM: Hemodynamic monitoring in sepsis. Crit Care Clin 2009, 25:802-823.

20. Murphy CV, Schramm GE, Doherty JA, Reichley RM, Gajic O, Afessa B, Micek ST, Kollef $\mathrm{MH}$ : The importance of fluid management in acute lung injury secondary to septic shock. Chest 2009, 136:102-109.

21. Rivers EP: Fluid-management strategies in acute lung injury - liberal, conservative, or both? N Engl J Med 2006, 354:2598-2600.

22. The National Heart, Lung, and Blood Institute Acute Respiratory Distress Syndrome (ARDS) Clinical Trials Network, Wiedemann HP, Wheeler AP, Bernard GR, Thompson BT, Hayden D, deBoisblanc B, Connors AF Jr, Hite RD, Harabin $A L$ : Comparison of two fluid-management strategies in acute lung injury. N Engl J Med 2006, 354:2564-2575.

23. Cain SM: Appearance of excess lactate in anesthetized dogs during anemic and hypoxic hypoxia. Am J Physiol 1965, 209:604-610.

24. Neill WA, Jensen PE, Rich GB, Werschkul JD: Effect of decreased $\mathrm{O}_{2}$ supply to tissue on the lactate:pyruvate ratio in blood. J Clin Invest 1969, 48:1862-1869.

25. Cady LD, Weil MH, Afifi AA, Michaels SF, Liu VY, Shubin H: Quantitation of severity of critical illness with special reference to blood lactate. Crit Care Med 1973, 1:75-80

26. Vincent J-L, Dufaye P, Berré J, Leeman M, Degaute JP, Kahn RJ: Serial lactate determinations during circulatory shock. Crit Care Med 1983, 11:449-451.

27. Mikkelsen ME, Miltiades AN, Gaieski DF, Goyal M, Fuchs BD, Shah CV, Bellamy SL, Christie JD: Serum lactate is associated with mortality in severe sepsis independent of organ failure and shock. Crit Care Med 2009, 37:1670-1677.

28. Revelly JP, Tappy L, Martinez A, Bollmann M, Cayeux MC, Berger MM Chiolero RL: Lactate and glucose metabolism in severe sepsis and cardiogenic shock. Crit Care Med 2005, 33:2235-2240.

29. Chioléro RL, Revelly J-P, Leverve X, Gersbach P, Cayeux MC, Berger MM, Tappy L: Effects of cardiogenic shock on lactate and glucose metabolism after heart surgery. Crit Care Med 2000, 28:3784-3791.

30. Levraut J, Ciebiera JP, Chave S, Rabary O, Jambou P, Carles M, Grimaud D: Mild hyperlactatemia in stable septic patients is due to impaired lactate clearance rather than overproduction. Am J Respir Crit Care Med 1998, 157:1021-1026.

31. Reinhart K, Bloos F: The value of venous oximetry. Curr Opin Crit Care 2005, 11:259-263.

32. Holm J, Hakanson E, Vanky F, Svedjeholm R: Mixed venous oxygen saturation predicts short- and long-term outcome after coronary artery bypass grafting surgery: a retrospective cohort analysis. $\mathrm{Br} J$ Anaesth 2011, 107:344-350.

33. Edwards JD: Oxygen transport in cardiogenic and septic shock. Crit Care Med 1991, 19:658-663.
34. Krafft P, Steltzer H, Hiesmayr M, Klimscha W, Hammerle AF: Mixed oxygen saturation in critically ill septic shock patients: the role of defined events. Chest 1993, 103:900-906.

35. Schmidt GA: Counterpoint: adherence to early goal-directed therapy. Chest 2010, 138:480-483.

36. Kern H, Wittich R, Rohr U, Kox WJ, Spies CD: Increased endothelial injury in septic patients with coronary artery disease. Chest 2001, 119:874-883.

doi: $10.1186 /$ cc13840

Cite this article as: Ouellette and Shah: Comparison of outcomes from sepsis between patients with and without pre-existing left ventricular dysfunction: a case-control analysis. Critical Care 2014 18:R79.

\section{Submit your next manuscript to BioMed Central and take full advantage of:}

- Convenient online submission

- Thorough peer review

- No space constraints or color figure charges

- Immediate publication on acceptance

- Inclusion in PubMed, CAS, Scopus and Google Scholar

- Research which is freely available for redistribution

Submit your manuscript at www.biomedcentral.com/submit
C) Biomed Central 